\section{Case Reports in Neurology}

Case Rep Neurol 2020;12:247-254

DOI: $10.1159 / 000507920$

Published online: July 1, 2020 (c) 2020 The Author(s)

Published by S. Karger AG, Basel www.karger.com/crn

This article is licensed under the Creative Commons Attribution-NonCommercial 4.0 International License (CC BY-NC) (http://www.karger.com/Services/OpenAccessLicense). Usage and distribution for commercial purposes requires written permission.

\title{
Fibrosing Inflammatory Pseudotumor Presenting as Cranial Neuropathy
}

\author{
Edison K. Miyawaki ${ }^{a} \quad$ Liangge Hsu $^{b}$ Shamik Bhattacharyya ${ }^{a}$ \\ Meabh J. O'Hare ${ }^{a} \quad$ Alexis Roy ${ }^{a}$ Lauren Kett ${ }^{a}$ Rachel A. Caplan ${ }^{a}$ \\ Lillian W. Dattiloc ${ }^{c}$ Vickie Y. Jo ${ }^{d}$ Jeffrey P. Guenette ${ }^{b}$ \\ aDepartment of Neurology, Brigham and Women's Hospital, Harvard Medical School, \\ Boston, MA, USA; 'Division of Neuroradiology, Brigham and Women's Hospital, \\ Dana-Farber Cancer Institute, Harvard Medical School, Boston, MA, USA; 'Harvard Medical \\ School, Boston, MA, USA; dDepartment of Pathology, Brigham and Women's Hospital, \\ Harvard Medical School, Boston, MA, USA
}

\section{Keywords}

Fibrosing inflammatory pseudotumor · Cranial mononeuropathy · Multiple cranial neuropathies

\begin{abstract}
We report two cases of biopsy-corroborated "fibrosing inflammatory pseudotumor" to illustrate that the entity, rarely described in the neurological literature, should be included in the differential diagnosis of either a cranial mononeuropathy or, certainly, in the case of progressive cranial neuropathies. A broad differential diagnosis arises in certain contexts. Early steroid treatment can be effective, and perhaps later-generation immune-modulating agents may confer further options, although there is no known definitive treatment.
\end{abstract}




\section{Case Reports in Neurology}

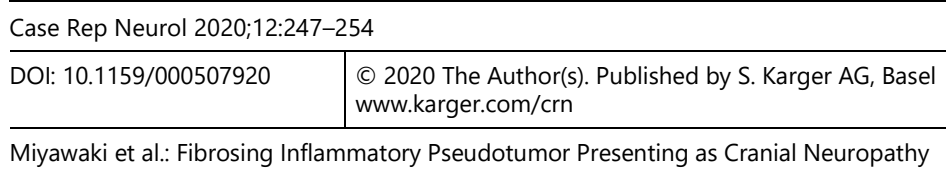

\section{Introduction}

The word "pseudotumor" for a neurologist connotes intracranial hypertension in the absence of intra- or extra-axial lesions to account for the raised pressure. As encountered in a wide-ranging literature, much of it outside of neurology, the term "fibrosing inflammatory pseudotumor" (FIP) refers to a non-specific, mixed inflammatory and fibrosing tumor-like process reported in the orbit in the early 20th century (reviewed in the 1970s under the name of "inflammatory orbital pseudotumor") [1, 2]; then, over time, FIP was identified in diverse locales, including lymph nodes [3], nasopharynx [4], and elsewhere [5]. "Pseudotumor" diagnoses in an older literature may refer to alternative etiologies, including, for example, IgG4related disease [6]; even in contemporary descriptions, etiology is uncertain or unknown.

We report two cases of FIP, with biopsies, presenting either as a single cranial neuropathy or as multiple cranial neuropathies.

\section{Case Presentations}

Case 1

A 57-year-old man with a past medical history of hypertension, hyperlipidemia, a traumaassociated splenectomy, and current tobacco use described an intermittent right temporal "pressure" headache dating to July 2019. Some months later, after he received a meningitis vaccine complicated by a red rash and swelling in the vaccinated arm, he noted horizontal double vision (worse with far than near vision) which corrected when he covered either eye. At an outside facility, a brain MRI exam was interpreted as normal. A myasthenia antibody panel was negative. Prednisone, $20 \mathrm{mg}$ orally per day, was started, and his double vision resolved.

Late in the year, upon discontinuation of prednisone after a taper, his double vision returned, now clearly worse when looking to the right, and right-sided headache recurred. He noted a high-pitched ringing in both ears. An EMG found no evidence for generalized myasthenia. Figure 1 includes pertinent images of a repeat brain MRI exam, which demonstrated subtle signal abnormalities in the clivus and overlying meninges. Oral dexamethasone $4 \mathrm{mg}$, four times per day, temporarily improved his vision and headache. His diplopia and tinnitus persisted with some improvement when converted to oral prednisone, $60 \mathrm{mg}$ daily. Results of a biopsy involving both otolaryngologic and neurosurgical approaches are summarized in Case 1's online supplementary data (for all online suppl. material, see www.karger.com/doi/10.1159/000507920). Alternative treatments were entertained, as discussed below.

\section{Case 2}

A 74-year-old man whose past medical and surgical histories were remarkable for idiopathic pulmonary fibrosis and bilateral lung transplantation in 2018 (with tacrolimus immunosuppression interrupted briefly with a course of cyclosporine), hypertension, hyperlipidemia, a peripheral neuropathy, a non-arteritic anterior ischemic optic neuropathy (eventually thought unrelated to tacrolimus), and chronic renal failure, reported a balance disturbance and an intermittent, right-sided, shooting headache that extended from the right ear to his right forehead in early 2019. An MRI exam in March demonstrated an infiltrative, enhancing, expansile soft tissue process in the right nasopharyngeal soft tissues that extended to the carotid space with involvement of the skull base towards the right foramen ovale. An 


\section{Case Reports in Neurology}

Case Rep Neurol 2020;12:247-254

DOI: $10.1159 / 000507920$

(c) 2020 The Author(s). Published by S. Karger AG, Basel www.karger.com/crn

Miyawaki et al.: Fibrosing Inflammatory Pseudotumor Presenting as Cranial Neuropathy

endoscopic nasal biopsy found chronic inflammatory changes without evidence of nasopharyngeal carcinoma or other malignancy. Case 2's supplementary data summarize relevant diagnostic studies and two sets of pathology results, from March, then August 2019. He was initially treated with ciprofloxacin for a presumed osteomyelitis.

By August, he noted persistent right, lancinating headache, similar in kind to that described previously, vision blurred to a greater degree than at baseline, a hissing sound in his right ear, and drooling. He now used a walker as a balance aid. An MRI exam re-demonstrated the right nasopharyngeal, non-specifically inflammatory process, now with an area of central necrosis, and extension of tumor into the right cerebellopontine angle. Cerebrospinal fluid revealed a total protein of 100.1 and a glucose of 49 , with 190 nucleated cells; $68 \%$ neutrophils, $25 \%$ mononuclears, and $7 \%$ lymphocytes. Routine, anaerobic, and mycobacterial cultures were negative, as were a cryptococcal antigen assay and cytology. Otolaryngologic resection with removal of mucosa and muscle to the clivus and petroclival junction was performed; he also underwent a neurosurgical debulking of the mass. Various medications and nerve blocks were tried unsuccessfully to manage his facial pain.

He re-presented in October, with ongoing right headache and frank horizontal diplopia, clearly worse on rightward gaze. He was no longer able to clear his secretions. An MRI exam demonstrated extension of inflammation into the internal auditory canal and cavernous sinus, both on the right. A CT bone exam demonstrated erosion of the right clivus (for selected MR and CT images, see Fig. 2, 3). The patient received a methylprednisolone pulse (250 mg intravenously for 3 days), then an oral prednisone taper with some improvement, but then a return of facial pain. A subsequent course of intravenous dexamethasone had no beneficial effect.

In mid-November, his neurological examination was notable for right greater than left ptosis, exquisite touch sensitivity in right V1, a right abducens palsy, poor elevation of the palate, right sensorineural hearing loss, and dyscoordinated tongue movements without lateralizing palsy. Palliative radiation was offered, along with plans for alternative immunosuppressive therapies. Later in the month, the patient opted for comfort measures close to his home. He died without opportunity for autopsy.

\section{Discussion/Conclusion}

An abbreviated differential diagnosis of the radiographic findings described in Figures 1, 2 , and 3 primarily includes: non-infectious inflammation, infection (including bacterial and atypical infections such as tuberculosis, fungi, or other fastidious organisms), lymphoma, and nasopharyngeal carcinoma. Secondarily, one could add bone metastasis and extramedullary plasmacytoma. None of the entities aside from FIP proved tenable in either of the patients described, and in light of the consistent demonstration of inflammation and fibrosis across biopsies, both were independently diagnosed as FIP.

A nonspecific, fibrosing inflammation as a diagnosis of exclusion does not capture the potentially progressive nature of FIP, as illustrated in case 2 . Correspondence between clinical symptoms and lesion sites may be less than precise or quite focal, if a cranial neuropathy is unequivocally present. The phrase "aggressive pseudotumor" applies to how FIP can mimic malignancy in terms of bony destruction, local infiltration, and associated obliteration of fascial and fat planes, though not all cases of FIP share that natural history [7, 8]. Perineurial spread along cranial nerves has been observed [9], but both our cases indicate an infiltrative and (in case 2) an expanding lesion associated with compression of nerves either at the skull base (e.g., foramen ovale, internal auditory meatus, jugular foramen) or in dura-lined cavities 


\section{Case Reports in Neurology}

Case Rep Neurol 2020;12:247-254

DOI: $10.1159 / 000507920$

(c) 2020 The Author(s). Published by S. Karger AG, Basel www.karger.com/crn

Miyawaki et al.: Fibrosing Inflammatory Pseudotumor Presenting as Cranial Neuropathy

(e.g., cavernous sinus or Meckel's cave). Hypointense or heterogeneous T2 signal intensity in the absence of calcification and weak gadolinium enhancement may suggest FIP rather than malignancy [4]. Our case 2 exhibited uniform and avid enhancement, such avidity has been reported [9], and (relatively late in the course) a hypodense area suggesting central necrosis. Bone marrow change resulting from bony involvement has also been described, as in our case 1 [7]. However, imaging features are non-specific and do not allow for definitive diagnosis in the absence of biopsy - and, indeed, multiple biopsies are often needed to establish FIP as a diagnosis of exclusion [5].

Any number of descriptive terms have been used to identify FIP pathologically. A short list includes: fibroinflammatory pseudotumor, sclerosing pseudotumor, and tumefactive fibroinflammatory lesion [10]. Variable histologic appearance accounts perhaps for even more FIP "synonyms," including plasma cell granuloma, mast cell granuloma, xanthogranuloma, histiocytoma, and inflammatory myofibroblastic/myofibrohistiocytic proliferation [11]. It is possible that morphological heterogeneity in any given sample in time relates to stages in the course of FIP, ranging from early inflammatory cell infiltration to late, often dense fibrosis, as has been speculated in FIP outside the nervous system [3].

Positive response to corticosteroids is widely acknowledged in FIP, although use of oral steroids after pathologic diagnosis (roughly a month after such diagnosis) may be less robust or ineffective [7]. In cases of extraorbital spread of orbital FIP, steroid treatment may not be necessary [12], but the recommendation not to treat may not apply to disease as described in our cases. The neutrophil-predominant pleiocytosis noted months after first symptoms in case 2 suggests that an acute or sub-acute phase exists in FIP. Early steroid treatment seems advantageous, as the partial response in case 2 and the early response in case 1 illustrate. Radiotherapeutic treatment has been used in only a small number of cases [8]; there is limited experience with use of mycophenolate mofetil [13], methotrexate [14], or monoclonal antibodies directed against either CD20 [13] or TNF- $\alpha$ (tumor-necrosis factor-alpha) [15], as was contemplated in both our cases.

The pathogenesis of FIP is open to debate and conjecture. "Some" inciting infection or exposure may be culpable [8], e.g. the vaccination history in case 1; yet, in case 2, a new Epstein-Barr PCR positivity occurred well into the course of his FIP; his immunocompromised state as a transplant recipient renders any exposure possible, but not proven by studies obtained (summarized in Case 2's online supplementary data).

In summary, we report two cases of biopsy-corroborated FIP to illustrate that the entity, rarely described in the neurological literature, should be included in the differential diagnosis of either a cranial mononeuropathy or, certainly, in the case of progressive cranial neuropathies. A broad differential diagnosis arises in certain contexts, necessitating a wide-ranging laboratory evaluation, as in the case of an immunocompromised host. Early steroid treatment can be effective, and perhaps later-generation immune-modulating agents may confer further options, although there is no known definitive treatment.

\section{Acknowledgements}

Biopsies were performed jointly by members of the Departments of Neurosurgery, Surgery (Otolaryngology), and Radiology (Diagnostic Radiology) at Brigham and Women's Hospital, including Drs. Ian Tafel, Timothy R. Smith, Jennifer Shin, Carlton Corrales, and Thomas C. Lee. The authors thank Dr. Umberto DeGirolami (Department of Pathology, Division of Neuropathology, Brigham and Women's Hospital) for his review of pathology in case 1. 


\section{Case Reports in Neurology}

\begin{tabular}{l|l}
\hline Case Rep Neurol 2020;12:247-254 \\
\hline DOI: $10.1159 / 000507920$ & $\begin{array}{l}\text { ( } 2020 \text { The Author(s). Published by S. Karger AG, Basel } \\
\text { www.karger.com/crn }\end{array}$ \\
\hline Miyawaki et al.: Fibrosing Inflammatory Pseudotumor Presenting as Cranial Neuropathy
\end{tabular}

\section{Statement of Ethics}

The patients described in this paper (or their guardians) have given written, informed consent to publish their cases, radiographic images, and pathological reports. The research in this paper was conducted ethically in accordance with the World Medical Association Declaration of Helsinki.

\section{Disclosure Statement}

The authors report no conflicts of interest.

\section{Funding Sources}

None.

\section{Author Contributions}

Dr. Miyawaki wrote the first draft of the paper which was reviewed by each author, all of whom contributed to the clinical care of one or both patients; authors' textual changes and additions were all incorporated. Drs. Hsu and Guenette contributed radiographic images and their interpretation. Dr. Jo interpreted the pathological samples in case 2.

\section{References}

1 Heersink B, Rodrigues MR, Flanagan JC. Inflammatory pseudotumor of the orbit. Ann Ophthalmol. 1977 Jan;9(1):17-29, 25-29.

2 Chavis RM, Garner A, Wright JE. Inflammatory orbital pseudotumor. A clinicopathologic study. Arch Ophthalmol. 1978 Oct;96(10):1817-22.

3 Moran CA, Suster S, Abbondanzo SL. Inflammatory pseudotumor of lymph nodes: a study of 25 cases with emphasis on morphological heterogeneity. Hum Pathol. 1997 Mar;28(3):332-8.

4 Choi SY, Yu IK, Han MH, Lee BH, Song CJ, Kim KS. Fibrosing inflammatory pseudotumor of the nasopharynx: MR features and histopathologic correlation. Eur J Radiol. 2009 Nov;72(2):274-7.

5 Hytiroglou P, Brandwein MS, Strauchen JA, Mirante JP, Urken ML, Biller HF. Inflammatory pseudotumor of the parapharyngeal space: case report and review of the literature. Head Neck. 1992 May-Jun;14(3):230-4.

6 Stone JH, Zen Y, Deshpande V. IgG4-related disease. N Engl J Med. 2012 Feb;366(6):539-51.

7 Han MH, Chi JG, Kim MS, Chang KH, Kim KH, Yeon KM, et al. Fibrosing inflammatory pseudotumors involving the skull base: MR and CT manifestations with histopathologic comparison. AJNR Am J Neuroradiol. 1996 Mar;17(3):515-21.

8 Weisman RA, Osguthorpe JD. Pseudotumor of the head and neck masquerading as neoplasia. Laryngoscope. 1988 Jun;98(6 Pt 1):610-4.

9 Gadde J, Franck B, Liu X, Teixido M, Rizk H. Inflammatory pseudotumor of the nasopharynx with spread along the trigeminal nerve. Am J Otolaryngol. 2013 May-Jun;34(3):252-4.

10 Sung MW, Kim KH, Lee CH, Moh JH, Kim WH, Han MH. Fibrosing inflammatory pseudotumors of the central skull base. Laryngoscope. 1997 Dec;107(12 Pt 1):1651-5.

11 Som PM, Brandwein MS, Maldjian C, Reino AJ, Lawson W. Inflammatory pseudotumor of the maxillary sinus: CT and MR findings in six cases. AJR Am J Roentgenol. 1994 Sep;163(3):689-92.

12 Mahr MA, Salomao DR, Garrity JA. Inflammatory orbital pseudotumor with extension beyond the orbit. Am J Ophthalmol. 2004 Sep;138(3):394-400.

13 Ortlip TE, Drake VE, Raghavan P, Papadimitriou JC, Porter NC, Eisenman DJ, et al. Inflammatory pseudotumor of the temporal bone: a case series. Otol Neurotol. 2017 Aug;38(7):1024-31. 
Case Reports in Neurology

\begin{tabular}{l|l}
\hline Case Rep Neurol 2020;12:247-254 \\
\hline DOI: 10.1159/000507920 & $\begin{array}{l}\text { @ 2020 The Author(s). Published by S. Karger AG, Basel } \\
\text { www.karger.com/crn }\end{array}$ \\
\hline
\end{tabular}

Miyawaki et al.: Fibrosing Inflammatory Pseudotumor Presenting as Cranial Neuropathy

14 Kim JS, Hong KH, Kim JS, Song JH. Medical therapy of maxillary sinus inflammatory myofibroblastic tumors. Am J Otolaryngol. 2016 Jul-Aug;37(4):376-8.

15 Kapadia MK, Rubin PA. The emerging use of TNF-alpha inhibitors in orbital inflammatory disease. Int Ophthalmol Clin. 2006;46(2):165-81.
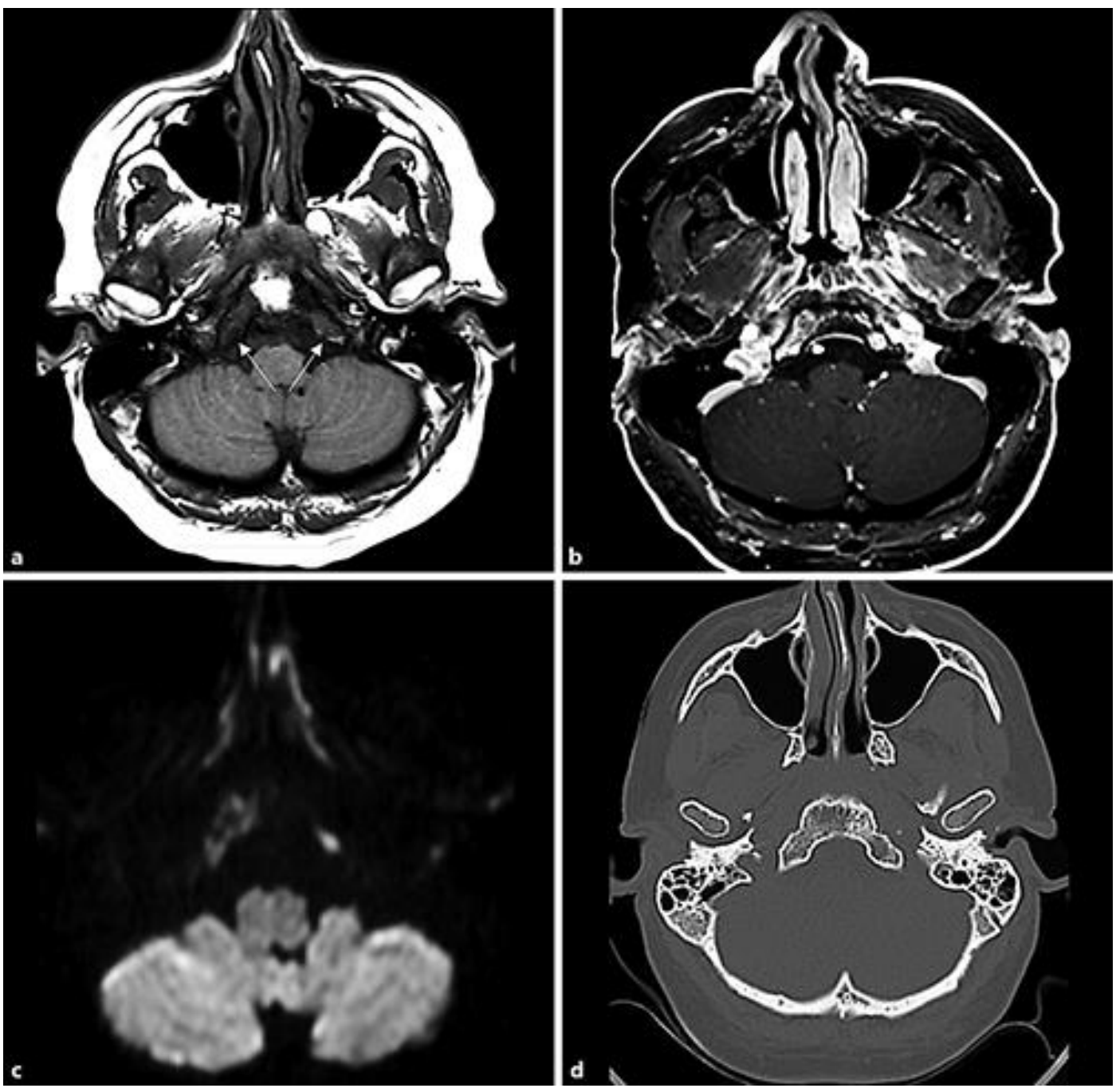

Fig. 1. Case 1. Axial pre-gadolinium (a) and post-gadolinium (b) images show loss of normal fatty signal of bilateral clivus (arrows) associated with enhancement. Corresponding DWI (c) and axial CT (d) images also demonstrate abnormal signal and attenuation, respectively. 


\section{Case Reports in Neurology}

\begin{tabular}{l|l}
\hline Case Rep Neurol 2020;12:247-254 \\
\hline DOI: 10.1159/000507920 & $\begin{array}{l}\text { @ 2020 The Author(s). Published by S. Karger AG, Basel } \\
\text { www.karger.com/crn }\end{array}$ \\
\hline
\end{tabular}

Miyawaki et al.: Fibrosing Inflammatory Pseudotumor Presenting as Cranial Neuropathy

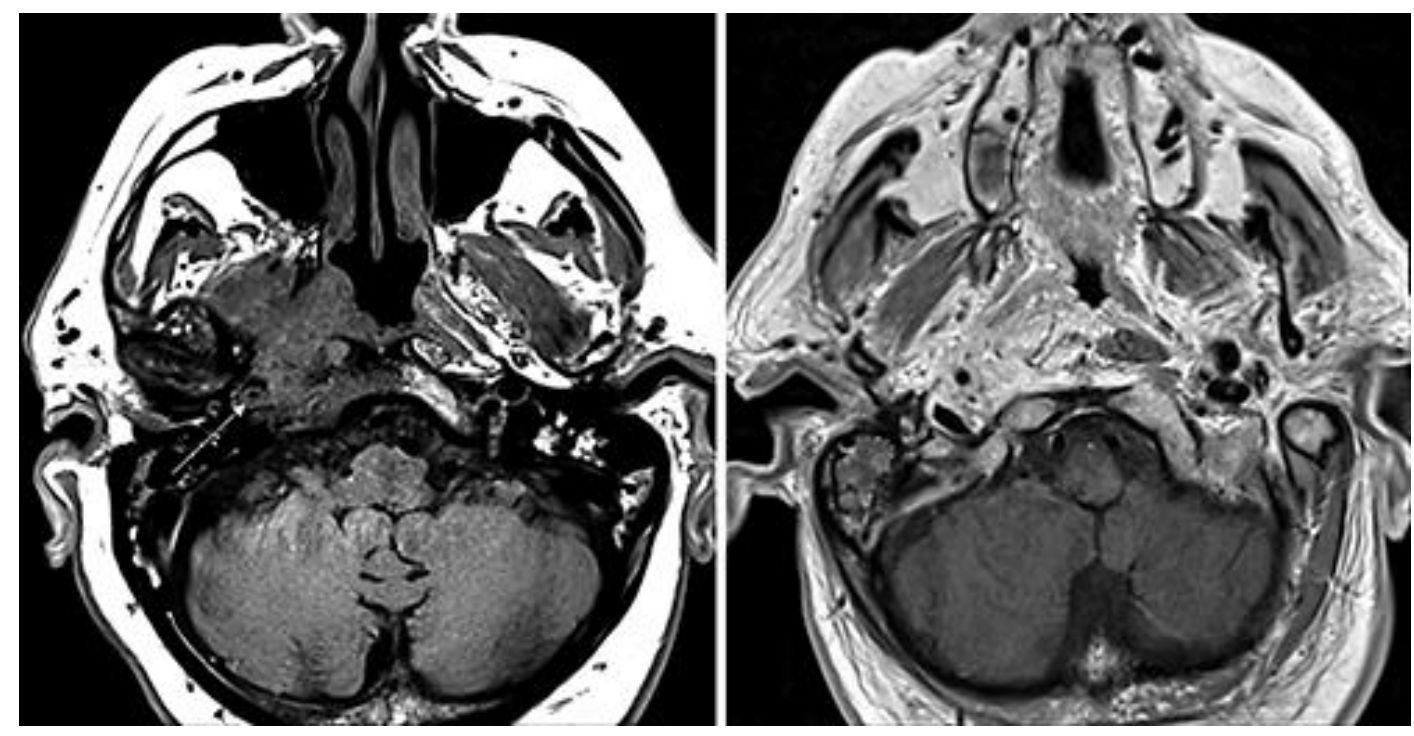

Fig. 2. Case 2. Pre-gadolinium (left) and post-gadolinium (right) axial T1 images through the nasopharynx show enhancing soft tissue on the right with extension to the right trigeminal fat pad, longus colli, and petrous bone, causing narrowing of the right petrous carotid artery (white arrow). There is also replacement of normal fatty marrow signal of the right clivus. 
Case Reports in Neurology
Case Rep Neurol 2020;12:247-254

DOI: $10.1159 / 000507920$ (c) 2020 The Author(s).
www.karger.com/crn

Miyawaki et al.: Fibrosing Inflammatory Pseudotumor Presenting as Cranial Neuropathy

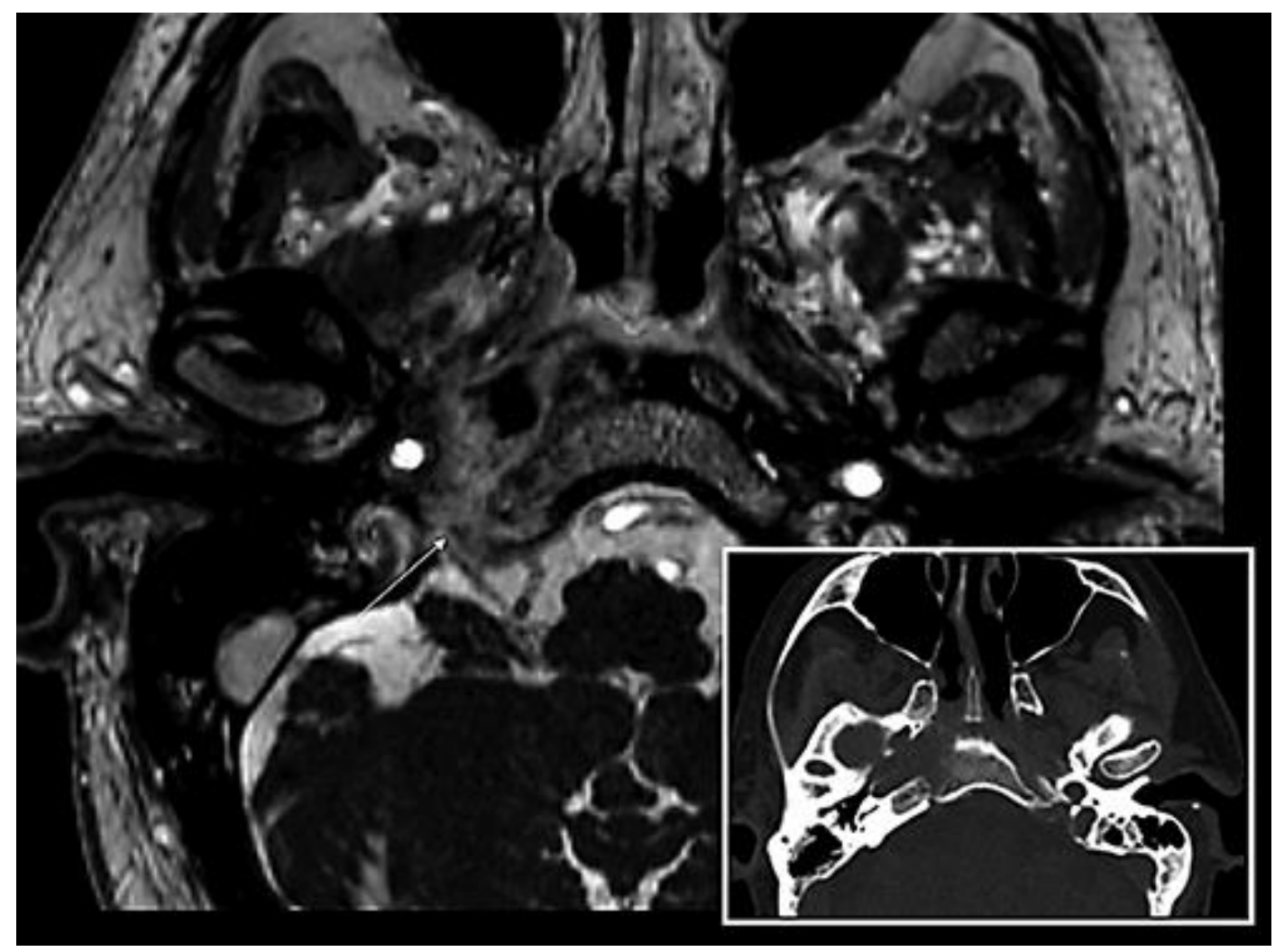

Fig. 3. Case 2. Axial CISS (construction interference in steady state) image demonstrates low-signal soft tissue extending into the anterior right jugular foramen (arrow). Inset: axial CT image shows lytic erosion of the right clivus. 